\title{
Construction of Biophysical Indicators for the Catalan Economy: Building a New Conceptual Framework
}

\author{
Carles Manera $^{1}$, Eloi Serrano ${ }^{2}$, José Pérez-Montiel ${ }^{1}\left(\mathbb{D}\right.$ and Màrian Buil-Fabregà ${ }^{2, *}$ \\ 1 Applied Economics Department, Universitat de les Illes Balears, 07122 Palma, Spain; \\ carles.manera@uib.es (C.M.); jose.perez@uib.es (J.P.-M.) \\ 2 General and Applied Economics Department, Tecnocampus, Universitat Pompeu Fabra, 08302 Mataró, Spain; \\ eserrano@tecnocampus.cat \\ * Correspondence: mbuil@tecnocampus.cat
}

check for

updates

Citation: Manera, C.; Serrano, E.; Pérez-Montiel, J.; Buil-Fabregà, M. Construction of Biophysical Indicators for the Catalan Economy: Building a New Conceptual Framework. Sustainability 2021, 13, 7462. https://doi.org/10.3390/ su13137462

Academic Editors: J.M. Raya and M. Buil-Fabregà

Received: 27 May 2021

Accepted: 27 June 2021

Published: 4 July 2021

Publisher's Note: MDPI stays neutral with regard to jurisdictional claims in published maps and institutional affiliations.

Copyright: (c) 2021 by the authors. Licensee MDPI, Basel, Switzerland. This article is an open access article distributed under the terms and conditions of the Creative Commons Attribution (CC BY) license (https:// creativecommons.org/licenses/by/ $4.0 /)$.

\begin{abstract}
The main objective of this work is to create an environmental vision of the Catalan economy based on various indicators. To do this, we started from the fundamental idea of obtaining new metrics to measure impacts on the economy. The methodology used is focused on the systematization of descriptive statistics and econometric review. In this sense, GDP and GDP per capita are valued as chrematistic units, and biophysical variables are incorporated. For the period 2000-2016, the figures for energy consumption, $\mathrm{CO}_{2}$ emissions, energy intensity of the economy and water consumption were collected. In addition, demographic evolution and the Gini index were also ordered as factors that contribute to explaining not only population trajectory but also some of the social factors. Greater technological efficiency in regard to environmental aspects is intuited as sensitive to the economic cycle. The study is novel in the panorama of the regional economy of Spain, by incorporating biophysical variables to the applied economic analysis.
\end{abstract}

Keywords: ecological economy (Q57); regional economy (R10); environmental impact assessment (Q51)

\section{Introduction}

Connecting economics with the natural sciences, such as linking biology and thermodynamics with economics, nuancing the excess of mathematical formalism, and emphasizing qualitative factors, is an important challenge for social scientists. The ability to relate chrematism and economics-in the Aristotelian sense of these concepts-can provide a much more accurate interpretive key to economic evolution. However, it cannot be said that no studies have focused on this close relationship, although with very different methodologies and theoretical approaches. The results have been cultivated mainly in the academic field and, in some cases, ideas and reflections have been transferred to active politics. The aspects covered can be grouped, broadly speaking, into two groups: issues that affect the environmental economy, and those that immerse themselves in the green economy. In the first case, the instruments applied are the neoclassically oriented aspects such as, for example, the willingness to pay to maintain a certain natural or landscape resource and approaches to its economic valuation. In the second case, non-chrematistic data have been used, of a biophysical nature-territorial consumption, waste production, pollution, etc.-without direct translation into prices. The distinction between price and value is very significant here; therefore, various indicators, such as ecological footprint or other indicators that include GDP alongside different variables such as life expectancy, educational level, or mortality, have been utilized in the social sciences [1,2]. These investigations have not, however, inferred the assumption of their results in public policies. This is a problem that dilutes sensations that are experienced in the economic landscape (sensations such as tourist saturation or spatial overwhelming), which urgently need to be quantified and made, above all, available in a data panel that is useful for public managers; 
specifically, the provision of specific quantities that facilitate decision-making. Its culmination would allow us to cross the border between research and application; the rise, in short, of economic policy.

The bibliographic foundations on these issues are abundant [3,4]. Of all contributions, the view on the laws of thermodynamics has become a crossroad for social scientists [5-8]. Here, again, the link between economics and the natural sciences emerges with solvency. In this sense, the assimilation of the principles of thermodynamics to economics [9] denotes assuming or taking into account the rules that come from biology, physics and chemistry. This author advocates an extension in the analysis of economic processes, incorporating methods and theories from the natural sciences, with a clear corollary: economic growth causes disorder in all areas and, obviously, in the environmental environment. That is why a precise dissection on the ecological impacts promoted by a certain type of growth is transcendental, and it is important to conduct measurements that are not limited to conventional parameters in academic economics. Thus, the research that has been developed specifies important aspects such as the qualities of the soil, the possible impact of climate on economic structure, and the economic and ecological transformation of the landscape, among others [10-12]. The social interweaving of these aspects is absolute, and economists and economic historians have worked on them; chronological proximity facilitates the availability of more robust data to perform economic analysis from this environmental perspective. These are considered essential ideas—based on [9] theses—that infer a methodological change:

- A critique of economic mechanisms; that is, of a linear, timeless view of economic evolution, so that qualitative elements are considered explanatory keys, aided by mathematics, but without submission to their excessive formalism that prevails in the teaching and research of economics;

- The idea of evolution, in biological terms; that is, the relevance of historical data, trajectory and time;

- The adoption of the concept of entropy, derived from thermodynamics; an argument that implies the thesis of the irreversibility - and even the irrevocability - of economic processes. The change is substantial. However, it contributes to enriching, technically and conceptually, the analysis of economics. This goes from a mechanistic phase, of a closed circular flow, to a holistic phase, in which the economist is impelled to discuss with other disciplines to better understand what is happening in their own discipline.

Therefore, essential concepts such as productivity and competitiveness, which are invariably invoked, are reinforced with others that have more porosity with those of physics, chemistry and biology: load capacity, efficiency, effectiveness, ecological footprint and intensity energy, are samples in this regard. In addition, another element is considered decisive: the technological [13]. This appears in the most popular economic models (and demanded in much of the research in economics) uncritically. It is an expected thing that will be able to solve, almost without discussion, any challenge we face, including the depletion of natural resources, which leads to a blind faith; an unbeatable confidence in technological progress that solves serious problems that shake and question economic growth. The philosophy that permeates these ideas comes from the discourses most assimilated by academic economics. These ideas fall under two precepts: the existence of infinite resources (thus, the scarcity of minerals is downplayed) and what has come to be described as energy theories of value; that is, the thesis that scientific development will provide all energy needed to recycle and thus the environment will remain natural and sustain economic growth continuously [14,15]. Therefore, materials are not and will not be a problem, as they can be recycled regardless of how much they are used. It is the "energy dogma" criticized by [9]; in turn, he points out that what characterizes an economic system is its institutions and not the technology that it uses. In our view, this last statement is something that every social scientist should never lose sight of in their research $[16,17]$.

This research focuses an empirical analysis on a very powerful regional economy in Spain, the economy of Catalonia. The economic process experienced by the Catalan 
economy has been characterized by a stylized fact: a predominance of the industrial sector, historically since the 19th century, in such a way that it constituted, together with the economy of the Basque Country, a tractor of Spanish industrial development. However, as a result of the transition to the service sector, which European economies have experienced since the 1960s, Catalonia has also had very decisive development in the service sector, to the point that it has surpassed the industrial sector and even dominates the structure regional economic. In this sense, it is important to introduce a different vision in the economic analysis, with the use of other metrics. The aim is to obtain new indicators that facilitate decision-making in the field of economic policy [18]. The study that is presented will require, in the future, a new challenge: the possibility of developing a synthetic index of environmental sustainability based on the results of this work and other contributions that complement it.

The work is organized as follows: After this introduction, in a second section, the objectives of the research and derived arguments are presented. Third, a sustained economic contextualization on technological change is realized, which is crucial to adopting new production processes that tend to reformulate the growth models and economics in a clear direction: the de-carbonization of the economy. Therefore, methodologies that measure the economy with different, non-chrematistic parameters are urgently needed. The fourth section of this work describes the indicators and the econometric interrelationships that are developed, with a purely empirical and descriptive character for the period 2000-2016. The research closes with qualitative conclusions derived from the previous sections.

\section{Objectives and Derived Arguments}

Under the parameters stated in the introduction, the present study has very specific and modest objectives: The adoption of a small battery of biophysical indicators, in direct relationship to the environment, to then determine the consequences that economic growth has on the environment. The period chosen is 2000-2016 for a central motivation: access to the required data and the setting of chronological coordinates that cover a phase of growth and a crisis (explained in more detail in point three of the work). It should be noted that the list of biophysical indicators is much more extensive and could be the subject of new research henceforth: water intensity, carbon equivalent, waste generated, etc. However, we think that what we propose can be very useful in the course of the research landscape.

Several factors of various kinds should be noted:

(a) In general, the matrix of correlations we built shows the close dependence between economic activity measured by GDP, energy and material flows, and their associated environmental impacts. Furthermore, it allows us to find differences and exceptions and to capture tendencies in the values of intensity;

(b) However, to know the total material requirement (or material intensity), one needs the balance of materials when using the EUROSTAT methodology [19-21]. The calculation in tones is interesting in order to break it down into fractions and identify, for example, the weight of construction materials, which makes it possible to compare the economic "weight" of this sector (in terms of sectoral value added to GDP, employment and wages) and the strict weight in material terms. Disaggregation between different types of materials makes it possible to separate the construction industry, for example, but it would also be possible to extend this to other sectors; for example, with the energy between transport, industry, services, etc. The only problem is that it requires energy and material balances. Furthermore, the physical balances of foreign trade can be calculated, as has already happened for much wider geographies;

(c) It is important to know the limits of each type of analysis depending on the methodology used to take them into account in the interpretation of results knowing what we can ask of them and what not. The way to count each indicator on its own terms and then to make correlations and obtain historical series of the evolution of intensities in terms of GDP seems better than the attempt to convert environmental impacts into monetary units, which results in only a purely chrematistic cost-benefit accounting. This could be 
a central idea of the more orthodox environmental economy, which seeks to reduce all ecological impacts into monetary terms. However, it is also necessary to know the limits of this type of research and, above all, what is the theoretical basis;

(d) In our analytical approach, there is still no theoretical model behind it, nor any criteria for establishing thresholds of sustainability or unsustainability. These thresholds can be included in the assessment, taking into account those that are already politically agreed upon (such as the Paris Climate Agreement, the IPCC recommendations, EU community objectives, the ecological transition in Spain, etc.). However, without a model behind it, prospective scenarios cannot be evaluated. That is, with our indicators, we present some useful criteria for the design of sectoral policies. However, in no case is a comprehensive design of a set of public policies that are oriented in an integrated way towards a fair transition aimed towards more sustainable scenarios. This is the great analytical challenge that we have ahead of us;

(e) In addition, this is also a great challenge in communicating to people a problem, that of the current unsustainability of the current economic model, which is intrinsically complex, multidimensional and multiscale. The combination of different indicators measured in different units is necessary. However, the multi criteria analysis becomes very complicated for it to be understandable to the general public. Additionally, reliable predictive scenarios should be developed. From here arise several initiatives, or lines of research, that seek to generate integrated analyses and synthetic indicators or indices:

- The ecological footprint was a first attempt, which has been very successful despite the large critical debate that it has provoked within the ecological economy. There are many arguments in favor of what is a bad indicator of environmental impact. A favorable argument is of a distributive nature: the ecological footprint captures the unequal appropriation of terrestrial bio capacity by the final consumption baskets of various populations of the world. However, it does so by taking for granted the technologies and ways of managing the average natural resources across the earth at any given time. Therefore, its diagnosis is not useful in generating prospective scenarios on how these technologies and forms of production and consumption can be changed and with what priorities to advance towards more sustainable scenarios;

- One step forward in the multi criteria line is Kate Raworth's "donut economics" [22]. There is a project with Kate Raworth's Donut Economics Lab (DEAL) to apply the "donut" to the city of Barcelona, a work led by Professor Enric Tello, of the University of Barcelona, without a doubt one of the leading experts in ecological economics and environmental history. Ref. [22] points out that we have not yet established a clear analytical and theoretical link between the "social foundation" to meet the basic needs of everyone with the "planetary boundaries", which we should not overcome on a global scale;

- A strong and effective response can utilize environmentally extended input-output analysis [23] (https:/ / www.exiobase.eu/, accessed on 12 May 2021; http:/ / www. wiod.org/home, accessed on 12 May 2021). I/O analyses are usually approached in a very conventional way. However, they can also make it possible to develop it into a reproductive line, linking the visions of $[9,24,25]$, which help to open new paths for research.

Based on these premises, we utilize precise, biophysical indicators, which can be modest, but also, effective information tools for public and private managers.

3. Changes in Service Economies in the Context of the Fifth Technological Revolution: A Context for Measuring the Economy with Other Parameters

\subsection{Economic Evolutionism}

The methodological approach of evolutionary economics allows us to analyze technological revolutions. This approach prioritizes the analysis of longwave capitalist development, understood as the unfolding of the economic effects caused by a given technological revolu- 
tion $[13,26-28]$. Thus, we focus on the characteristics of the current technological revolution in which we are immersed, based on information and communication technologies (ICT).

All technological revolutions are characterized in their beginning periods as bringing crises and very accentuated changes that give a tone of uncertainty and turbulence to the period of time under study. The changes cover not only the economic but also the social, political and institutional spheres and are not consolidated until later in the installation period. That is why it is possible to see where future institutional changes may crystallize that may favor a possible period of deployment of the current technological revolution on a global scale. Changes in the technological paradigm cause a stir in the international organization of work and call into question the progress made by all countries in the previous stages of development if they are not able to keep pace with the technical progress imposed by the countries that are leading the technological change.

The dynamics of the international economy, especially the main European economies, condition the temperament of the Catalan economy during these years because, by its industrial and tourist specialization, it is one of the most internationalized regional economies of the state. In this globalized economy, it is possible to find dynamic regularities and recurring sequences of change in the internal functioning of the capitalist system. This needs to be transformed and evolved through great technological revolutions, which end up causing waves of development. It is Schumpeter's well-known concept of "creative destruction", which saw capitalism as a process of industrial change that constantly revolutionizes the economic structure from within, uninterruptedly destroying what is old and continually creating new elements. Thus, each technological revolution gives birth to a new society that, to make its way, must transform the old structures created by the previous technological paradigm through the changes introduced by the technological revolution, with the consequent transformations of financial capital, productive capital and changes in the institutional framework that regulate the dynamics of economic growth and social development.

The current telecommunication technological revolution, which generates a new technological pattern of advanced services, has opened up a universe of new business opportunities and the appropriation of benefits for all pioneers who have ventured to walk through the industries of the new economy based on microelectronics and the cluster that conforms to all technologies related to the computer revolution. This has promoted the emergence not only of the hardware industry but also of the software industry, as well as the need for new telecommunication equipment that has made possible the birth of the internet. In addition, this has led to a series of new technologies with strong development potential, such as biotechnology, bioelectronics, nanotechnology and the internet [29,30]. Tourism has had radical transformative effects, both in terms of the profile of demand and in terms of its effects on intermediation and tourist transport and on the offer of tourist services and accommodation in multifamily housing, mainly in the urban nuclei of large cities. It is the birth of a new economic and social problem, which is not easy to manage by public authorities. Moreover, it has important ecological externalities [31-33].

\subsection{A State of Continual Uncertainty}

The end of a technological revolution and the beginning of a new technological big bang always represents a time of upheaval and economic, institutional and social crises. Only with crisis can the old be distinguished from the new and give way to the new; similar to the sap of a tree, this fuels the implementation of a new techno economic paradigm. It is estimated that this requires a maturation time of no less than two or three turbulent decades of transition. From the second half of the 1960s, the traditional industries of mass consumer goods and services (cars, appliances, mass tourism, etc.) faced the problems arising from the saturation of markets, falling demand, increases in costs, slowing productivity growth and ultimately a falling profit rate. However, the emerging markets of the fifth technological revolution are still too weak and unconsolidated to propel the new economy. This is the situation that defines the crossroad that the main Western economies are experiencing, 
between the maturity phase of the fourth technological revolution and the beginning of ICT in the early 1970s. Moreover, all were aggravated by the coronavirus pandemic, which started in 2020.

Technological change not only has limited effects in the field of production but is also important in highlighting the changes in the organizational sphere that have been experienced over the years. The connection between environment and technology, which can be deduced from the results obtained, is not addressed in this research. Its analysis requires a specific, extensive study, which goes beyond the purposes of the approach in this research, which has been defined above. The authors propose future research lines on this connection [34-36].

The authors basically refer to the introduction of flexible production systems based on decentralized organizational networks but interconnected with each other through a strategic core and a fast ICT-based communication system. One of the most important aspects of the period of installation of the current technological revolution in ICT and the knowledge society is how it affects the new international division of labor. The location of the big bang (or starting point of the new technological revolution) is important because it identifies which country is leading economic leadership. Each technological revolution originally takes place in a core country, which acts as the world economic leader from which the new revolution radiates to the most advanced countries. In this respect, SpainCatalonia to a lesser extent, attending to the projects inserted in the 22@ district, among other important initiatives-was initially left out of the big bang represented by new ICT that its potential developer began. The 22@ district is an already developed project of urban change and integration of new economic activities related to technology. The collaboration between public administrations, companies, universities and research centers, allowed the recovery of an urban public space that was formerly very degraded. At present, the 22@ technology district is an important pole of economic development and the capture of business experiences linked to Industry 4.0. This technological gap makes it more difficult for countries or regions that experience this gap to benefit from the new wave of economic growth and social welfare that involves the implementation of a new technological, economic and social paradigm.

However, some countries, spurred by the new wave of technology, may force the intensity of new investments and shorten the technology gap, which is known as catching up; it is even feasible to overtake the pioneering country in the technological revolution (forging ahead). It can be said that, in a world of accelerated change, countries or regions that do not adapt to change or that do not do so at the same rate as other countries may fall behind; that is, they may experience setbacks in their process of development. That is why, in these years of change, a situation of decline can be seen in the central countries, where the previous phase of maturation is already very advanced and the resumption of the new technological revolution has not yet begun; while in peripheral countries, due to its delay, there may be an extension of a stage of economic prosperity. We are therefore facing a period of bifurcation, where central economies are already aware of the turmoil of the new growth model, while peripheral economies, further behind in technological development, still enjoy the prosperity of the previous paradigm.

One of the key elements that allows for the visualization of the delayed institutional aspects of technological change and technical progress in countries that suffer from technological gap processes, or even fall behind, is the decisive role played by financial institutions. This is because the protagonists of technical change are usually pioneers who are not part of the core of the economic establishment [13]. If financial capital is not willing to perform risky operations and is reluctant to finance the demand for credit from new entrepreneurial talent, who are making radical innovations, it will become, in this case, a powerful force behind economic and social progress. Therefore, attention should be given to the attitude of this capital towards the relevant projects of decarbonization of economies with an agenda of ecological transformation and mode of production. 
In the case of Spain and Catalonia, the number of opportunities to find technologically radical and attractive investments by financial capital is lower in relation to the most technologically developed countries. These new business opportunities that new technology companies in the private sector can offer depend, in many cases, on the fact that they can enjoy a highly developed technological environment. Here, the public sector must play a leading role and lead, as has been the case in the United States for more than a hundred years, in what is now known as national innovation systems [37].

Recently, the existence of zombie companies has been strongly introduced as a lagging element in technical change and productivity growth in the economies of southern Europe (especially in the cases of Italy and Spain). Marginal companies' survival depends on banks not executing their credit defaults; therefore, their credit-assisted viability or renewal of low-interest loans (especially in Italy) harms the growth of more efficient, more innovative companies with a higher advance in labor productivity. In return, a lower growth in the aggregate productivity of the economy is generated, estimated at a loss of $1.2 \%$, caused by an increase of $3.5 \%$ in the proportion of zombie or marginal companies in the period 2005-2015 and in all nine OECD countries (Belgium, Spain, Finland, France, the United Kingdom, Italy, Korea, Sweden and Slovenia). In the case of Italy or Spain, this negative effect increases by $2 \%$. That is, this [38] OECD study also confirms results for the U.S. economy: marginal companies should be cleaning up. This cleaning is ascribed to the Rüstow effect [39], which ends up occurring in the phases of business reconversion, which generate economic crises, and which is characterized as a modality of the phase of reconversion and business restructuring, with recovery of surpluses and loss of employment. In this contractionary phase of demand, the decrease in employment-which infers positive growth in productivity (phase of forced recovery of labor productivity) - is already lower than the positive growth in the unit surplus per worker, which results in a resumption of the surplus, with the consequent unblocking of investments. This makes it feasible to open a new self-sustaining process of economic growth. It is the typical stage of industrial reconversion, where the disappearance of marginal companies is taken advantage of by those who have resisted the crisis to occupy new market shares. In addition, there is an acceleration in the process of innovation and renewal of the productive apparatus due to the need to open new markets. All this explains why a resumption of productive investments has begun in the absence of self-sustained growth in demand.

It is in this context where we must place the goal of obtaining new economic metrics which utilize the environment as a central element, i.e., the economy depends on nature and not the other way around [40-44].

\section{Methodology}

\subsection{Description}

The Catalan economy has evolved in recent years towards a clear process of deindustrialization and progress in the service sector. This is clearly seen in Tables 1 and 2 . It is important to observe this economic structure to be able to correctly analyze the question of new metrics in economic analysis, which is pursued in this research.

Table 1. Evolution of sectoral economic growth in the Catalan economy.

\begin{tabular}{ccccc}
\hline Years & Agriculture & Industry & Building & Services \\
\hline 2001 & -4.34 & 4.17 & 7.36 & 2.24 \\
\hline 2002 & 11.25 & -1.99 & 4.7 & 4.67 \\
\hline 2003 & 5.27 & 0.58 & 3.79 & 4.68 \\
\hline 2004 & -8.73 & 1.65 & 3.36 & 5.2 \\
\hline 2005 & 8.79 & -2.17 & 5.14 & 5.71 \\
\hline 2006 & -1.08 & 1.48 & 7.81 & 4.96 \\
\hline
\end{tabular}


Table 1. Cont.

\begin{tabular}{ccccc}
\hline Years & Agriculture & Industry & Building & Services \\
\hline 2007 & 0.31 & 0.57 & 1.17 & 5.28 \\
\hline 2008 & 1.52 & -4.85 & -2 & 1.1 \\
\hline 2009 & 1.84 & -12.12 & -7.03 & -0.78 \\
\hline 2010 & 1.86 & 6.44 & -19.58 & 1.86 \\
\hline 2011 & 7.67 & 0.11 & -10.4 & 0.8 \\
\hline 2012 & -15.35 & -4.9 & -18 & -1 \\
\hline 2013 & 6.86 & -1.4 & -10.9 & -0.2 \\
\hline 2014 & 1 & 2.7 & -1.4 & 1.5 \\
\hline 2015 & -3.38 & 5.8 & 4.23 & 2.6 \\
\hline 2016 & 2.84 & 3.36 & 6.76 & 2.87 \\
\hline
\end{tabular}

Source: own elaboration based on Idescat: http://economia.gencat.cat/ca/ambits-actuacio/economia-catalana trets/estructura-productiva/dades-basiques/ (accessed on 12 May 2021).

Table 2. Sectoral composition of the GDP of the Catalan economy.

\begin{tabular}{cccccc}
\hline Years & Agriculture & Industry & Building & Services & Total \\
\hline 2001 & 1.74 & 26.58 & 9.98 & 61.7 & 100 \\
\hline 2002 & 1.53 & 25.13 & 10.24 & 63.1 & 100 \\
\hline 2003 & 1.46 & 24 & 10.36 & 64.18 & 100 \\
\hline 2004 & 1.26 & 23.37 & 10.66 & 64.71 & 100 \\
\hline 2005 & 1.24 & 21.91 & 11.33 & 65.52 & 100 \\
\hline 2006 & 1.19 & 21.15 & 11.92 & 65.74 & 100 \\
\hline 2007 & 1.06 & 20.48 & 11.6 & 66.86 & 100 \\
\hline 2008 & 0.98 & 19.71 & 11.35 & 67.96 & 100 \\
\hline 2009 & 1.02 & 17.81 & 10.94 & 70.23 & 100 \\
\hline 2010 & 0.94 & 18.95 & 8.44 & 71.67 & 100 \\
\hline 2011 & 0.95 & 19.02 & 7.19 & 72.84 & 100 \\
\hline 2012 & 0.96 & 18.77 & 5.75 & 74.52 & 100 \\
\hline 2013 & 1.07 & 19.18 & 4.94 & 74.81 & 100 \\
\hline 2014 & 1.01 & 19.49 & 4.75 & 74.75 & 100 \\
\hline 2015 & 0.94 & 20.02 & 4.77 & 74.27 & 100 \\
\hline 2016 & 0.95 & 19.88 & 4.96 & 74.21 & 100 \\
\hline
\end{tabular}

Source: own elaboration based on Idescat: http://economia.gencat.cat/ca/ambits-actuacio/economia-catalana/ trets/estructura-productiva/dades-basiques/ (accessed on 12 May 2021).

The agricultural sector has lost weight in the total GDP, going from $1.7 \%$ in 2000 to $0.9 \%$ in 2016. The industry, which in 2000 generated $26.9 \%$ of Catalan GDP, fell to $19.8 \%$ in 2016. Between 2010 and 2016, it gained weight slightly (up to 20.0\%). Construction fell from a high of $11.9 \%$ in 2006 (and values above 10\% during the period 2002-2009) to 4.9\% in 2016. Since then, it has regained weight slightly, up to at 5.3\% in 2019. The services sector gained 13.1 percentage points in the productive structure of the Catalan economy between 2001 and 2013 (up to 74.8\%). The process where the services sector dominates is obvious. However, as indicated, this new orientation of the Catalan economy (with a loss of industrial prominence) does not eliminate the negative environmental externalities, although the indicators we have built suggest improvements in energy efficiency.

To answer the objectives raised in this paper, eight indicators were processed for the period 2000-2016. This interval of years includes a stage of remarkable economic growth 
that ended in 2008 with the beginning of the Great Recession, and a stage of stagnation that lasted until practically the last two years of the period, when the Catalan economy began a slow recovery. Some comments are peremptory:

(a) The indicators should help us to infer the evolution of biophysical data in relation to the intensity of the economic development of Catalonia and thus have an initial idea of Catalan economic development in relation to variables related to natural resources;

(b) It is in this sense that variables specific to the analysis of economic growth are incorporated, such as GDP, GDP per capita or the Gini Index, with environmental variables;

(c) The period considered, which includes different economic cycles, helps us to better understand the behavior of this relationship in changing scenarios; the data allow a study that, while not providing a very long-term view, includes a time interval long enough to make inferences from the object of study of this research with consistent robustness;

(d) The authors are aware they are working with aggregate data from Catalonia; that is, they are not broken down according to the Catalan provinces, a project that would require much more time and dedication than available.

The sources available for Catalonia allow us to work with the following indicators (see Appendix A at the end of the text):

- Energy consumption;

- Water consumption;

- $\mathrm{CO}_{2}$ emissions (mostly, although data on other gases was obtained);

- Energy intensity of the economy;

- Gini Index;

- Demographic Evolution;

- GDP;

- GDP (per capita).

These indicators have been chosen according to two important parameters. In the first place, because of its explanatory capacity, which also links with other case studies $[34,36]$. Waste and gas emissions are emphasized, while determining consumption such as energy and water are underlined. The indicators are therefore highly explanatory if, in addition, they are related to the evolution of GDP. The chrematistic gives way, thus, to the economy.

The eight indicators and their reciprocal relationships are characterized, always taking into account demographic evolution, because:

- They do not present unattainable methodological difficulties for data collection and subsequent calculation;

- The chrematistic variables (GDP and GDP per capita) can be integrated with the environmental variables $\left(\mathrm{CO}_{2}\right.$ emissions, energy use and water consumption) to obtain descriptive indicators;

- They help to identify some ecological effects of economic growth;

- They provide a different reading of the growth process, as they specify and systematize scattered variables that do not usually appear in the periodic diagnoses of different agents.

The basic idea, made later for all of them and others, that can be incorporated is to create an indicator as synthetic as possible that provides an environmental vision of the Catalan economy. It must be emphasized that a certain degree of imperfection is assumed and that the indicator could be more complete and incorporate more variables; however, the work performed shows how this approach can represent a first step towards future deeper research that expands the analytical framework and understanding of the results presented in it. Tables 3 and 4 show the absolute data and index numbers to make the comparison easier. Figures 1 and 2, in turn, mark the evolution; although Figure 2, which synthesizes a grouped processing of the variables, allows us to differentiate the chronological phases. 
Table 3. Basic indicators for the Catalan economy (2000-2016).

\begin{tabular}{|c|c|c|c|c|c|c|c|c|}
\hline Year & Population & GDP & $\begin{array}{c}\text { GDP } \\
\text { Deflactor }\end{array}$ & $\begin{array}{c}\text { GDP } \\
\text { Deflated at } \\
200 \text { Values }\end{array}$ & Gini Index & $\begin{array}{c}\text { Energy } \\
\text { Consumption } \\
\text { (ktep) }\end{array}$ & $\begin{array}{c}\text { Water } \\
\text { Consumption }\end{array}$ & $\begin{array}{c}\mathrm{CO}_{2} \\
\text { Emisions }\end{array}$ \\
\hline 2000 & $6,261,999$ & 127,605 & 104,384 & 122,246 & & 13,512 & 288 & 53,858 \\
\hline 2001 & $6,361,365$ & 136,952 & 102,881 & 131,200 & & 14,132 & 286 & 51,463 \\
\hline 2002 & $6,506,440$ & 145,947 & 104,493 & 139,817 & & 14,327 & 266 & 50,299 \\
\hline 2003 & $6,704,146$ & 156,673 & 103,627 & 150,093 & 0.320 & 15,280 & 253 & 53,805 \\
\hline 2004 & $6,813,319$ & 169,931 & 103,627 & 162,794 & 0.322 & 15,785 & 238 & 55,506 \\
\hline 2005 & $6,995,206$ & 183,581 & 104,058 & 175,871 & 0.311 & 15,970 & 219 & 57,341 \\
\hline 2006 & $7,134,697$ & 199,153 & 103,842 & 190,789 & 0.323 & 15,817 & 234 & 56,157 \\
\hline 2007 & $7,210,508$ & 212,244 & 103,093 & 203,330 & 0.322 & 16,188 & 237 & 57,006 \\
\hline 2008 & $7,364,078$ & 216,220 & 104,275 & 207,139 & 0.322 & 15,596 & 208 & 53,222 \\
\hline 2009 & $7,475,420$ & 206,813 & 100,200 & 198,127 & 0.327 & 14,761 & 192 & 49,894 \\
\hline 2010 & $7,512,381$ & 208,593 & 102,041 & 199,832 & 0.321 & 14,861 & 193 & 49,137 \\
\hline 2011 & $7,539,618$ & 208,341 & 103,413 & 199,591 & 0.326 & 14,221 & 190 & 46,588 \\
\hline 2012 & $7,570,908$ & 201,768 & 102,987 & 193,294 & 0.319 & 13,609 & 189 & 44,198 \\
\hline 2013 & $7,553,650$ & 201,531 & 101,729 & 193,067 & 0.330 & 13,002 & 170 & 41,029 \\
\hline 2014 & $7,518,903$ & 204,896 & 100,100 & 196,291 & 0.323 & 12,999 & 169 & 41,284 \\
\hline 2015 & $7,508,106$ & 213,746 & 99,800 & 204,769 & 0.314 & 13,330 & nd & 42,012 \\
\hline 2016 & $7,522,596$ & 222,514 & 100,100 & 213,169 & 0.318 & 13,521 & 172 & 43,320 \\
\hline
\end{tabular}

Source: own elaboration based on Appendix A.

Table 4. Reduced indicators to index $2000=100$.

\begin{tabular}{|c|c|c|c|c|c|c|c|c|c|}
\hline Year & $\begin{array}{l}\text { Real GDP } \\
\text { Per Capita }\end{array}$ & $\begin{array}{l}\text { Energy Con- } \\
\text { sumption } \\
\text { (ktep) }\end{array}$ & $\begin{array}{l}\text { Water Con- } \\
\text { sumption }\end{array}$ & $\begin{array}{c}\mathrm{CO}_{2} \\
\text { Emissions }\end{array}$ & $\begin{array}{l}\text { Energy } \\
\text { Consump- } \\
\text { tion/GDP }\end{array}$ & $\begin{array}{l}\mathrm{CO}_{2} \text { Emis- } \\
\text { sions/GDP }\end{array}$ & $\begin{array}{c}\text { Efficiency of } \\
\text { Water Con- } \\
\text { sumption }\end{array}$ & $\begin{array}{c}\text { Efficiency } \\
\text { of Energy } \\
\text { Use }\end{array}$ & $\begin{array}{c}\text { Efficiency } \\
\text { of } \mathrm{CO}_{2} \\
\text { Emissions }\end{array}$ \\
\hline 2000 & 100 & 100 & 100 & 100 & 100 & 100 & 100 & 100 & 100 \\
\hline 2001 & 105 & 104.59 & 99.31 & 95.55 & 97.92 & 90.58 & 106.22 & 107.73 & 110.4 \\
\hline 2002 & 110 & 106.03 & 92.36 & 93.39 & 93.15 & 84.97 & 119 & 117.99 & 117.68 \\
\hline 2003 & 115 & 113.08 & 87.85 & 99.9 & 92.55 & 87.25 & 130.35 & 123.72 & 114.62 \\
\hline 2004 & 122 & 116.82 & 82.64 & 103.06 & 88.15 & 84.33 & 147.88 & 138.63 & 118.58 \\
\hline 2005 & 129 & 118.19 & 76.04 & 106.47 & 82.55 & 82.8 & 169.1 & 155.77 & 120.78 \\
\hline 2006 & 137 & 117.06 & 81.25 & 104.27 & 75.37 & 76.24 & 168.33 & 181.47 & 131.17 \\
\hline 2007 & 144 & 119.81 & 82.29 & 105.85 & 72.38 & 73.39 & 175.26 & 199.27 & 136.26 \\
\hline 2008 & 144 & 115.42 & 72.22 & 98.82 & 68.45 & 68.69 & 199.2 & 210.19 & 145.58 \\
\hline 2009 & 136 & 109.24 & 66.67 & 92.64 & 67.73 & 68.34 & 203.33 & 200.15 & 146.33 \\
\hline 2010 & 136 & 109.98 & 67.01 & 91.23 & 67.61 & 67.06 & 203.02 & 201.24 & 149.12 \\
\hline 2011 & 135 & 105.24 & 65.97 & 86.5 & 64.77 & 63.89 & 205.23 & 209.03 & 156.52 \\
\hline 2012 & 131 & 100.72 & 65.63 & 82.06 & 64.01 & 62.85 & 198.98 & 204.01 & 159.12 \\
\hline 2013 & 131 & 96.22 & 59.03 & 76.18 & 61.22 & 58.27 & 221.46 & 213.53 & 171.6 \\
\hline 2014 & 134 & 96.2 & 58.68 & 76.65 & 60.2 & 57.41 & 227.54 & 221.79 & 174.19 \\
\hline 2015 & 139 & 98.65 & & 78.01 & 59.18 & 55.92 & & 235.71 & 178.82 \\
\hline 2016 & 145 & 100.06 & 59.72 & 80.43 & 57.66 & 55.5 & 242.68 & 251.35 & 180.19 \\
\hline
\end{tabular}




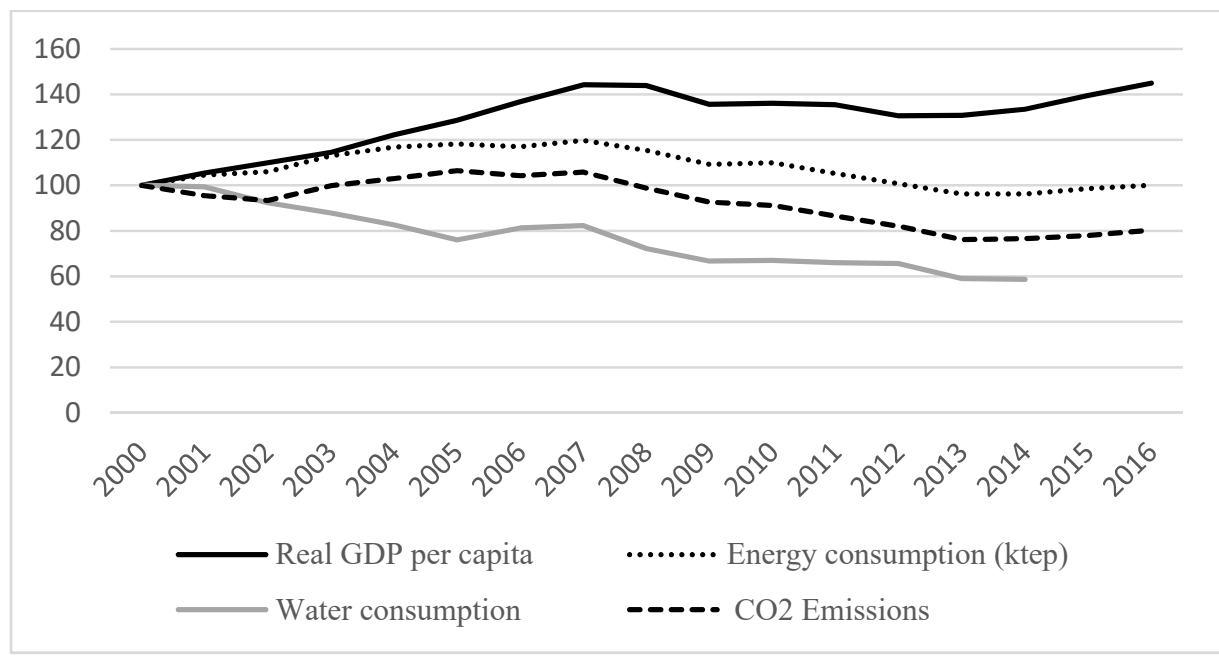

Figure 1. Descriptive evolution $(2000=100)$. Source: own elaboration based on Appendix A.

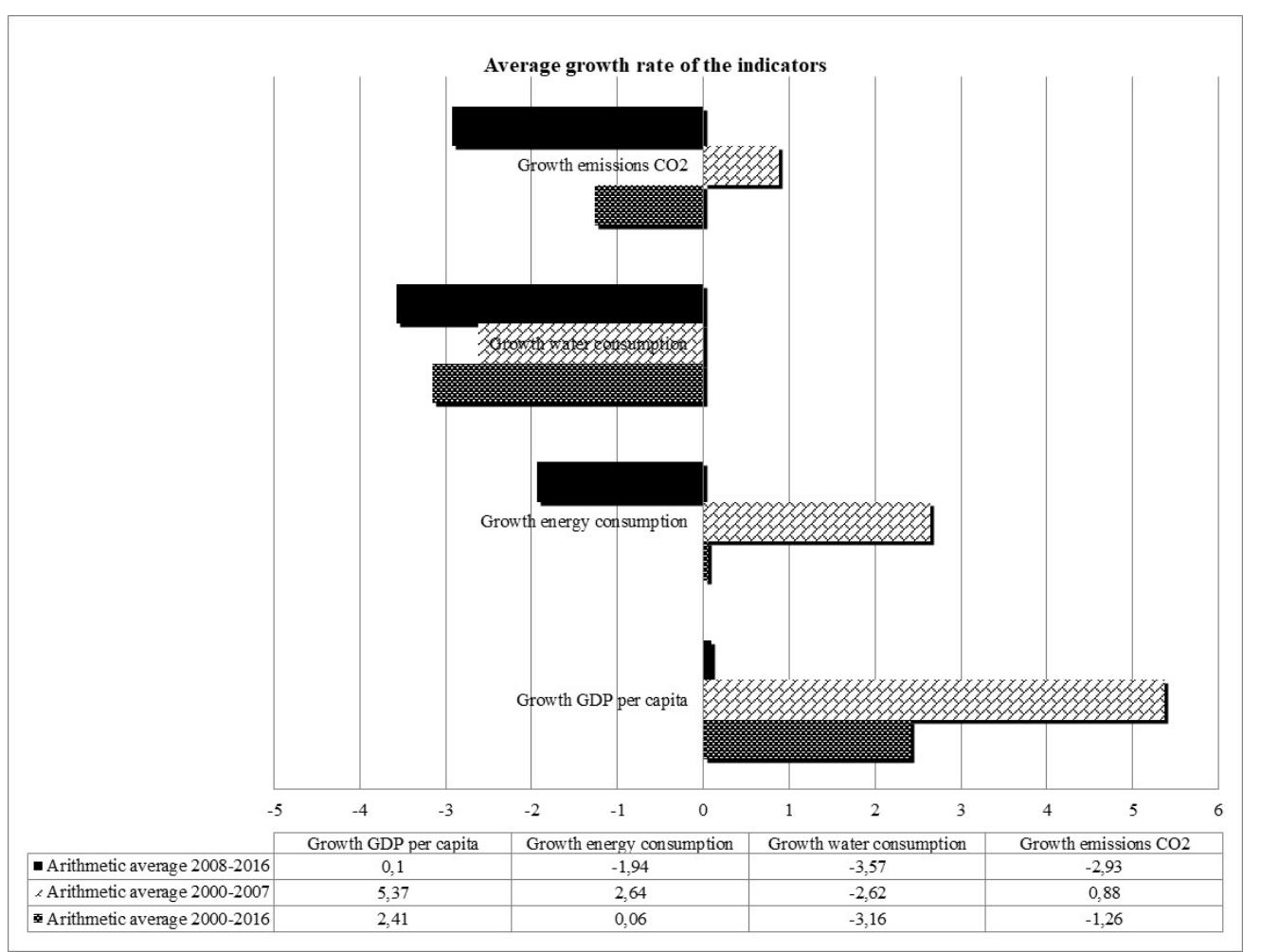

Figure 2. Average growth rate indicators. Source: own elaboration based on Appendix A.

Reading these data allows us to determine two specific stages in our series: 2000-2007 and 2008-2016. The figures show:

- GDP grew robustly between 2000 and 2007, before the outbreak of the Great Recession. The data are in line with an increase in energy consumption (GDP per capita: 5.37; energy consumption: 2.64), while $\mathrm{CO}_{2}$ emissions increase at a rate of 0.88 ;

- The Great Recession laminates the advance of GDP per capita, which is in a steady state between 2008 and 2016; eight years, therefore, of anemic growth in the production of material wealth. At that time, the biophysical indicators experienced a significant decrease: -1.94 energy, -3.57 water consumption and $-2.93 \mathrm{CO}_{2}$ emissions;

- The aggregate data for the two different periods provide more information: GDP per capita 2000-2016 has increased at a fairly acceptable rate, which is explained by 
the growth momentum in the first of the phases. It is significant that the rest of the variables considered are below the growth of GDP per capita, with the sole exception of water consumption.

These three considerations are complemented by the arrangement of growth rates, which is shown in Table 5 .

Table 5. Growth rate of indicators.

\begin{tabular}{ccccc}
\hline Year & GDP Per Capita & Energy Consumption (ktep) & Water Consumption & CO $_{2}$ Emissions \\
\hline 2000 & & & & -4.45 \\
2001 & 5.49 & 4.59 & -0.69 & -2.26 \\
2002 & 4.19 & 1.38 & -6.99 & 6.97 \\
2003 & 4.18 & 6.65 & -4.89 & 3.16 \\
2004 & 6.72 & 3.31 & -5.93 & 3.31 \\
2005 & 5.22 & 1.17 & 6.85 & -2.06 \\
2006 & 6.36 & -0.96 & 1.28 & 1.51 \\
2007 & 5.45 & 2.35 & -12.24 & -6.64 \\
2008 & -0.25 & -3.66 & -7.69 & -6.25 \\
2009 & -5.78 & -5.35 & 0.52 & -1.52 \\
2010 & 0.36 & 0.68 & -1.55 & -5.19 \\
2011 & -0.48 & -4.31 & -0.53 & -5.13 \\
2012 & -3.56 & -4.30 & -10.05 & -7.17 \\
2013 & 0.11 & -4.47 & -0.59 & 0.62 \\
2014 & 2.14 & -0.02 & & 1.76 \\
2015 & 4.47 & 2.54 & & 3.11 \\
\hline
\end{tabular}

Source: own elaboration based on Appendix A.

A survey of the evolution of these indicators suggests the following:

1. The Catalan GDP in 2016 was $23.78 \%$ higher than that in 2000, while the GDP per capita was $4.3 \%$. The increase in the population of Catalonia stood at $18.53 \%$. This circumstance shows an increase in GDP, driven, among other factors, by an increase in population; therefore, the data indicate how this increase in production was insufficient to maintain the GDP per capita in stable and constant terms during the period studied. The productive structure of Catalonia, therefore, has not been able to generate a growth rate of GDP above the growth rate of the population. The constant GDP $($ Base $=2000)$ from Idescat, in millions of EUR. The result is derived from multiplying the deflator of the year 2000 by real GDP. The GDP per capita $($ Base $=2000)$ based on Idescat, is obtained by dividing the constant GDP (Base $=2000$ ) by the population;

2. Environmental data show some behaviors that, in some cases, are surprising because they show a clearly downward trend. Water consumption was ostensibly reduced, and energy use had a residual increase of approximately $1 \%$ for the entire period, while $\mathrm{CO}_{2}$ emissions were reduced by $20.22 \%$ (see Table 3 again).

Energy consumption shows a constant decrease for the entire period, with the exception of the rise of 2006 and 2007, while the number of liters per inhabitant and day decreases systematically and is quite detached from the economic cycle. Energy consumption, however, experienced a rather significant cumulative increase for the period 2000-2007 and a decline in subsequent years; there is a strong relationship with the economic cycle, expansive for the first half of the series and recovery for the second. However, we can see that in the first years of recovery, after the Great Recession, consumption remained at levels below the pre-crisis period. $\mathrm{CO}_{2}$ emissions, on the other hand, showed a decreasing trend in the period 2000-2016. Although they increased in the years of greatest economic dynamism, with the recession, emissions fell significantly and, with the recovery, they have increased but not at pre-economic crisis levels.

There is, then, a tendency towards an improvement in environmental indicators. Despite the economic growth experienced for the entire period, these indicators have, in 
almost all of them, a downward behavior. The most obvious manifestation is the intensity of the use of resources, which is shown in Figure 3. In fact, energy intensity decreased considerably from 2000 to a base of 100 to 58 in 2016, a very significant reduction that was constant throughout virtually the entire period (except for the years 2003 and 2004). This contrasts with the evolution of the curves in Figure 4: the so-called "productivity" of the resources inserted in the production processes. The evolution is, logically, the inverse of that observed in Figure 3. All this supports the idea of a better, more efficient use of biophysical inputs for the achievement of Catalan GDP, which is also linked to its demographic variable, GDP per capita.

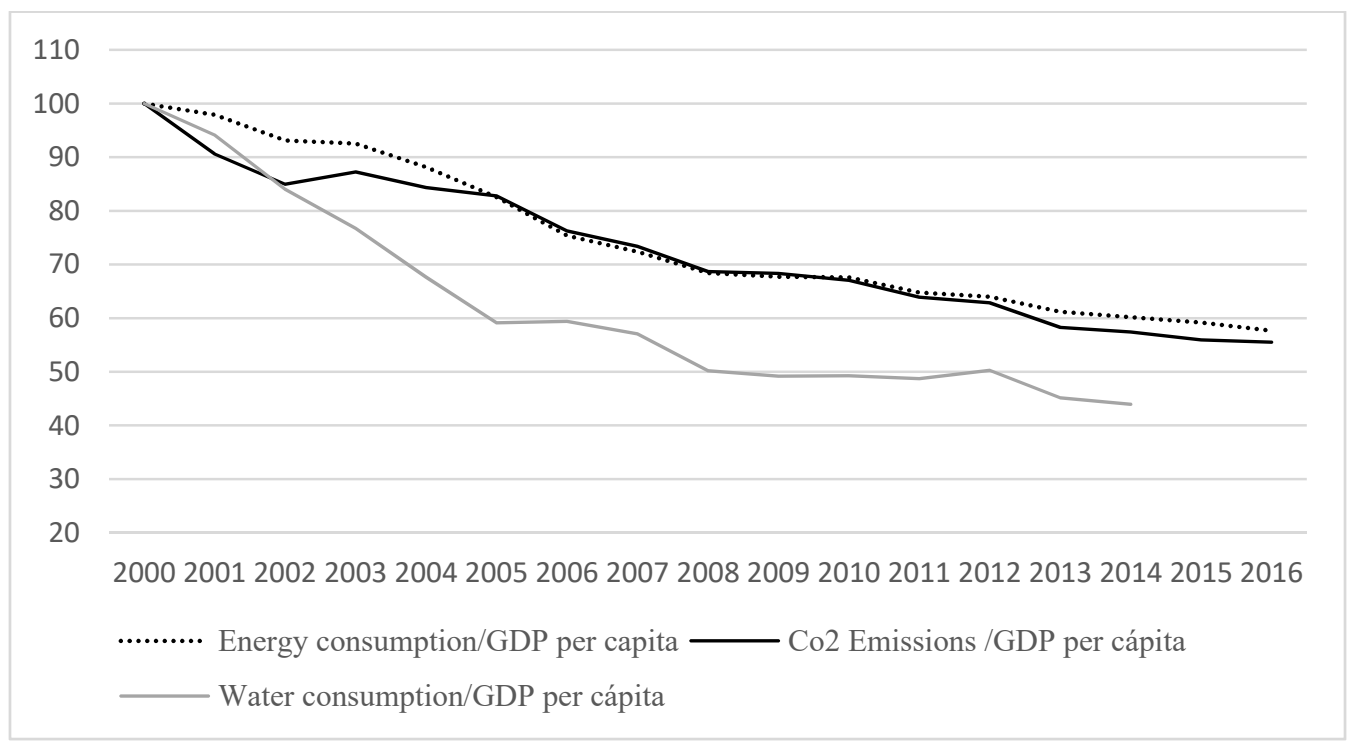

Figure 3. Use intensity of resources $(2000=100)$. Source: own elaboration based on Appendix A.

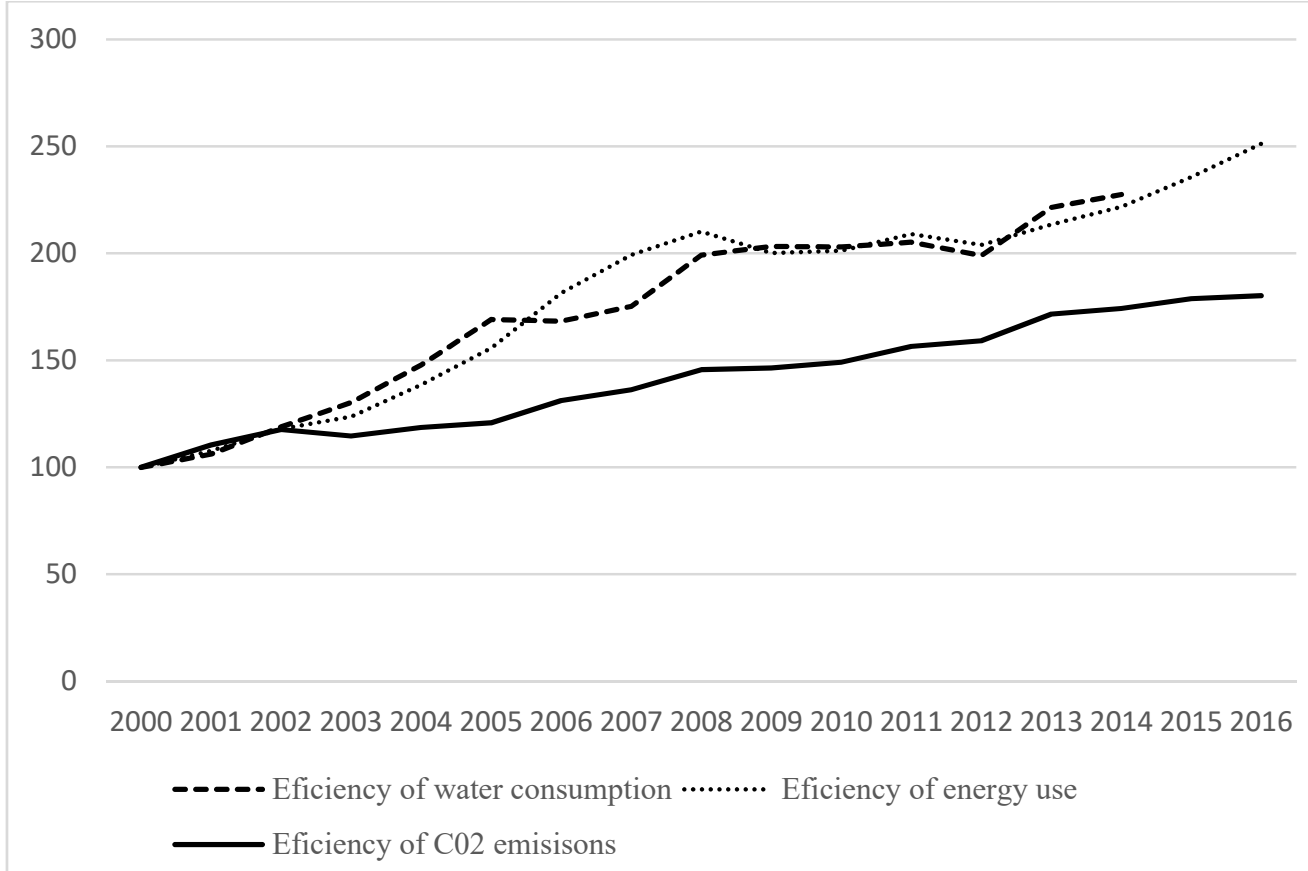

Figure 4. Resource efficiency (the inverse of the intensity). Source: own elaboration based on Appendix A. 
From here, it is more complicated. They are shown in Figures 5-7 with their specific comments:

(a) Figure 5 shows the relationship between GDP per capita and $\mathrm{CO}_{2}$ emissions: positive increases (decreases) in GDP which leads to increases (decreases) in $\mathrm{CO}_{2}$ emissions. However, emissions systematically increase less than GDP per capita. For example, in the total period 2000-2016, GDP per capita increased by $45 \%$, while $\mathrm{CO}_{2}$ emissions decreased by $20 \%$. This is mainly because, since the 2007 crisis, decreases in GDP per capita imply proportionally larger decreases in $\mathrm{CO}_{2}$ emissions than increases in the period 2000-2007 (for example, between 2007 and 2013, GDP per capita decreased by 9\%, while $\mathrm{CO}_{2}$ emissions decreased by $28 \%$ ). Therefore, we can suggest that, during the economic recession, greater efficiency lowered $\mathrm{CO}_{2}$ emissions.

(b) As with $\mathrm{CO}_{2}$ emissions, the ratio between GDP per capita and energy consumption in Figure 6, is positive (increases (decreases) in GDP infer increases (decreases) in energy consumption). As in the previous case, energy consumption systematically increases less than GDP per capita; for example, in the period 2000-2016, GDP per capita expanded by $45 \%$ and energy consumption remained unchanged. Again, this is mainly because, since the 2007 crisis, decreases in GDP per capita have in turn lowered proportionally larger energy consumption than increases in the period 2000-2007 (for example, between 2007 and 2013, GDP per capita decreased by $9 \%$, while energy consumption decreased by $19 \%$ ). Therefore, we hypothesize that, during the economic recession, efficiency in energy consumption increased.

(c) The case of water consumption-Figure 7-is different from that of $\mathrm{CO}_{2}$ emissions and energy consumption. The figure shows that water consumption has not stopped declining (with the exception of the period 2005-2007). Thus, GDP per capita increased by $45 \%$ in $2000-2016$, while water consumption fell by $40 \%$.

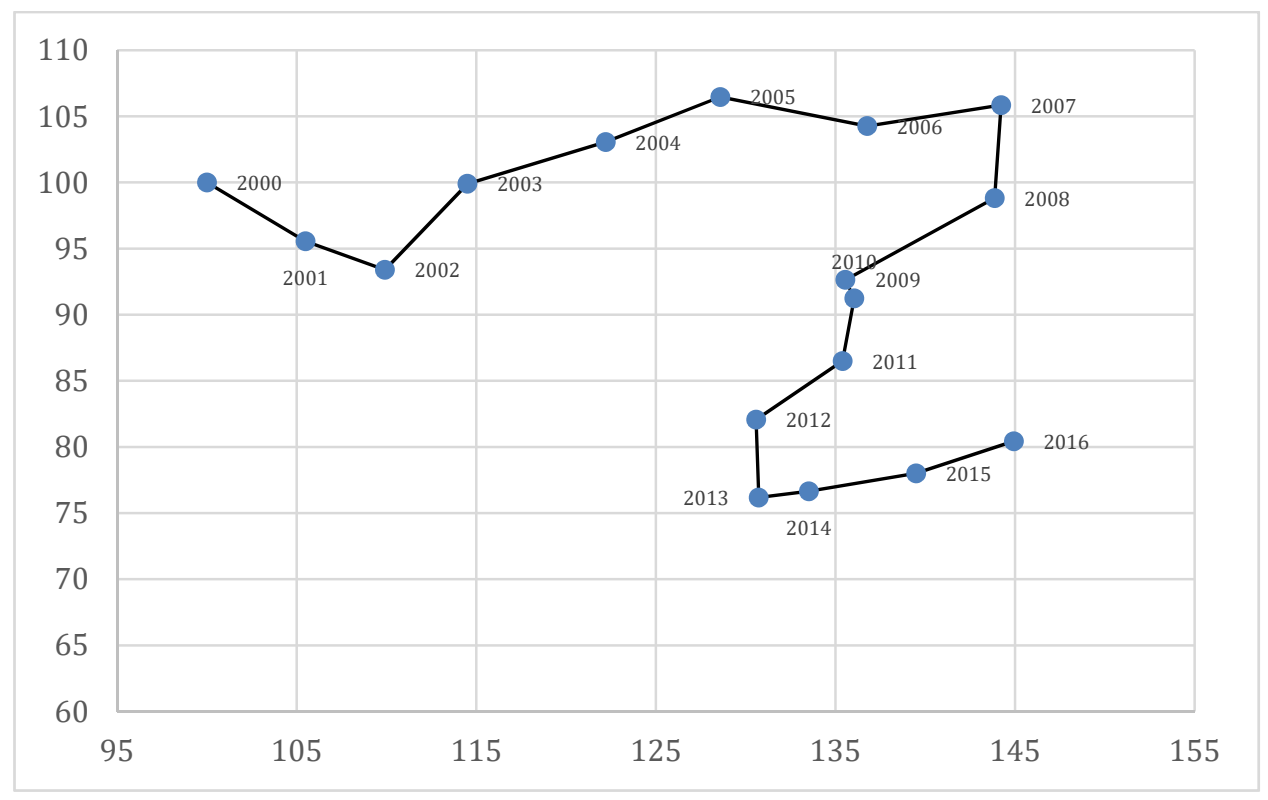

Figure 5. GDP per capita (horizontal axis) and $\mathrm{CO}_{2}$ emissions (vertical axis). Source: own elaboration based on Appendix A. 


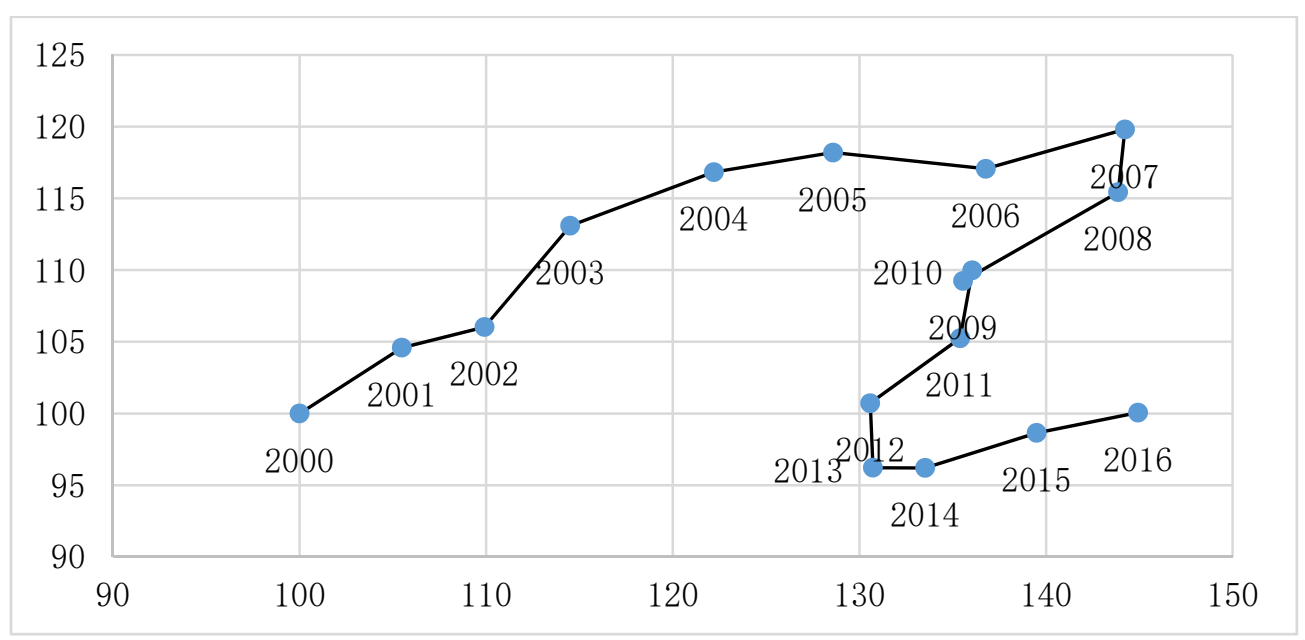

Figure 6. GDP per capita (horizontal axis) and energy consumption (vertical axis) $(2000=100)$. Source: own elaboration based on Appendix A.

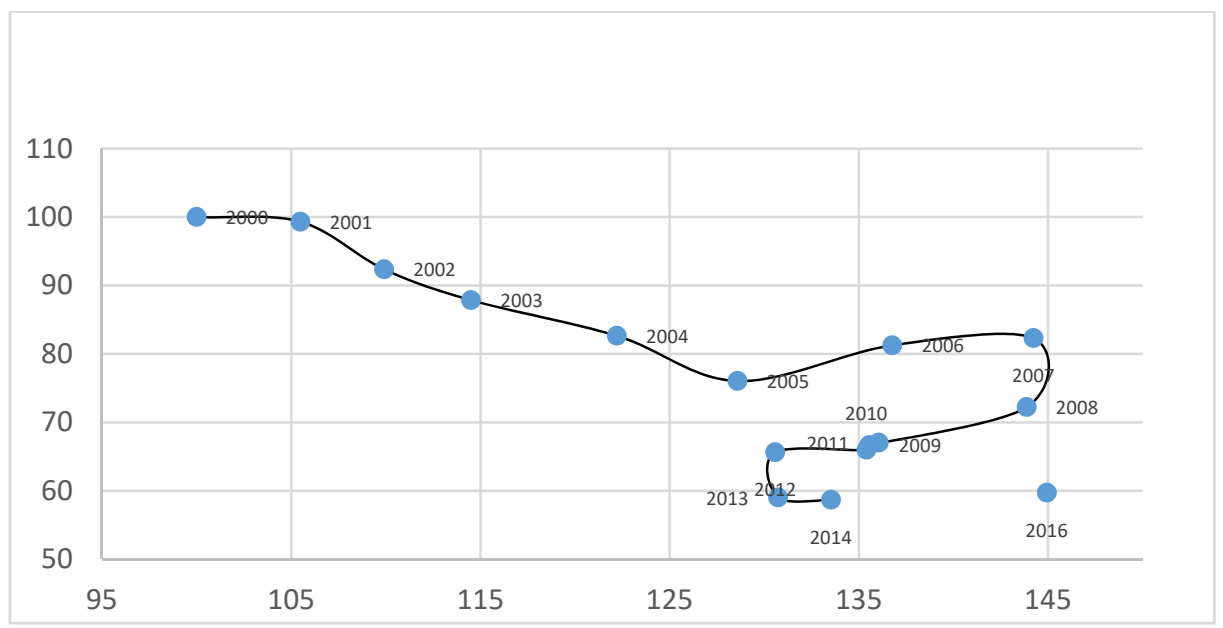

Figure 7. GDP per capita (horizontal axis) and water consumption (vertical axis) $(2000=100)$. Source: own elaboration based on Appendix A.

\subsection{Analysis of Main Components}

This study will use the analysis of the main components (ACP) method to capture the general characteristics and trends of the use of natural resources in Catalonia (we explain in Appendix B). This method makes it possible to synthesize the information contained in $\mathrm{W}, \mathrm{E}$ and $\mathrm{CO}_{2}$ and avoids the subjectivity and rigidity of the weights given to each variable when synthesizing various indicators of the use of natural resources.

We will use the ACP method to develop a synthetic indicator of the use of natural resources, which we will call CI_PC. ACP is based on a linear transformation of variables; therefore, they are orthogonal to each other [39]. Thus, the main component is one that maximizes the variance of the data, rather than minimizing the minimum square distance between them. In short, the ACP method transforms data into new variables (i.e., major components) that are not correlated with each other. The ACP method can be applied to the original values of the variables, to the deviations of their means or to the standardized variables. In this study, we adopt the last procedure because $\mathrm{W}, \mathrm{E}$ and $\mathrm{CO}_{2}$ are not measured in the same units. Therefore, we transform the variables into logarithms.

Before using the $\mathrm{ACP}$ method, we perform some preliminary data testing. To ensure the use of ACP, we applied the Bartlett sphericity test (BTS), adequacy test and KaiserMeyer-Olkin (KMO) adequacy test. As expected, the results of the BTS test suggest the 
rejection of the null hypothesis that the correlation matrix is an identity matrix (all zeros except those of the main diagonal) at the significance level of $1 \%$. The result of the KMO measurement of sampling adequacy is 0.70 (greater than 0.50), indicating that there are major common factors between the variables and a strong linear relationship between them, which is suitable for the ACP method. Both tests support the suitability of the ACP method.

Once we verified the suitability of the use of ACP in our study, we applied the method. First, we obtained the number of components using the Kaiser-Guttman rule. Table 4 shows the proportions of the variance of the eigenvalue to select the optimal number of components. According to the Kaiser-Guttman rule, only one component can be retained because only the first component has an eigenvalue greater than one.

As seen in Table 6 , the first component represents $78 \%$ of the cumulative contribution rate, which can explain most information from the original variables. This indicates that it is only necessary to use the first main component when synthesizing our index of resource use in Catalonia (CI_PC).

Table 6. Eigenvalues of the reduced correlation matrix.

\begin{tabular}{ccccc}
\hline Component & Proper Value & Difference & Proportion & Accumulative Proportion \\
\hline 1 & 2.34 & 1.76 & 0.78 & 0.78 \\
2 & 0.63 & 0.59 & 0.21 & 0.99 \\
3 & 0.02 & & 0.01 & 1 \\
\hline
\end{tabular}

Finally, we estimated the correlation matrix between CI_PC and our variables of interest (GDP, W, E and $\left.\mathrm{CO}_{2}\right)$, which is shown in Table 7.

Table 7. Correlation matrix.

\begin{tabular}{cccccc}
\hline & $\mathbf{W}$ & $\mathrm{CO}_{2}$ & $\mathbf{E}$ & $\mathbf{C I}_{\mathbf{P C}}$ & PIB \\
\hline $\mathrm{W}$ & 1 & & & & \\
$\mathrm{CO}_{2}$ & 0.74 & 1 & & & \\
$\mathrm{E}$ & 0.38 & 0.86 & 1 & 1 & \\
$\mathrm{CI}_{\mathrm{PC}}$ & $\mathbf{0 . 7 9}$ & $\mathbf{0 . 9 9}$ & $\mathbf{0 . 8 6}$ & $-\mathbf{0 . 2 7}$ & 1 \\
$\mathrm{PIB}$ & -0.75 & -0.23 & 0.21 & \\
\hline
\end{tabular}

CI_PC is highly correlated with each original variable $\left(\mathrm{W}, \mathrm{E}\right.$ and $\left.\mathrm{CO}_{2}\right)$. We also observe a high correlation between the original variables $\left(\mathrm{W}, \mathrm{E}\right.$ and $\left.\mathrm{CO}_{2}\right)$, which helps to explain why the first main component alone explains $94 \%$ of the total variation in $\mathrm{W}, \mathrm{E}$ and $\mathrm{CO}_{2}$, which makes the reduction of the data highly effective. We can see that CI_PCi GDP per capita is negatively correlated. This may be indicative of a negative relationship between economic growth and the use of natural resources. However, since our research is merely descriptive, more research is needed in this regard.

\section{Conclusions}

The presented work includes specific conclusions but, furthermore, opens up new avenues for research. We can point out the following:

- The research started from the fundamental idea of obtaining new metrics to measure the impacts from the economy;

- These measures are necessarily incomplete. Other researchers and institutions-such as the fundamental CADS - have data batteries that complement and enrich the proposals here. It is important to emphasize this because we are well aware that we need to work with holistic views and to be clear that we are facing a path that is wide open, both for researchers and policy makers;

- In this sense, GDP and GDP per capita are valued as chrematistic units. However, it is thought that there is an urgent need to establish other biophysical variables that contrast with the more conventional indicators mentioned above;

- The figures for energy consumption, $\mathrm{CO}_{2}$ emissions, energy intensity of the economy and water consumption were collected for the period 2000-2016 using the Idescat 
bases in a preeminent way (Tables 1 and 2). In addition, demographic evolution and the Gini index were also ordered as factors that contribute to explaining not only the population trajectory but also some of the social factors. We know that observations are very limited. However, we are not unaware that they from, as was said, a departure from other scenarios that must be more ambitious;

- The methodology used includes descriptive statistics for data processing. In parallel, the main component analysis model was also used to establish a better synthesis between the variables analyzed and the degree of cohesion, if any, between them;

- An inflection point is observed in the period treated of 2007-2008, that is, the start of the Great Recession. The economy is still affected by the aftermath of the crisis and, in return, this affects biophysical indicators. Then, the direct relationship between economic growth and ecological externalities is presented.

- However, the entire period shows a behavior that should be noted: the inverse relationship between the evolution of GDP and that of the set of biophysical variables (Tables 1 and 2). That is, the following points can be noted:

- Greater technological efficiency in production processes indicates that environmental impacts are lower than theoretically expected, depending on the evolution of GDP;

- $\quad$ The possible consequences of the tertiarization of the Catalan economy, with losses of industrial infrastructure, are presumably more polluting than the activities of services.

- Work, from here, opens up a range of possibilities. Some of them are:

- Expanding the chronological margin depends on the reliable availability of sources. Pulling the series "backwards" and providing more data forward can build a more robust statistical set;

- Connecting the work with the Sustainable Development Goals (SDGs) that the Catalan government is working on, under the coordination of the CADS and with the commitment of the ministries and the Presidency of the Catalan Government called Generalitat;

- Deepening a disaggregation of the variables, going to provincial territories, so that this would enrich the understanding of the binomial economic growth-ecological impact in Catalonia, with a geographical vision;

- Landing in the microeconomic field, with business analyses that allow us to obtain accurate information on possible processes of the circular economy. This represents a pedagogical factor aimed at the business world, from the moment that working from the perspective of measuring the economy-and the microeconomics - under biophysical parameters, can be, in fact, a factor of competitiveness in markets that increasingly value the efforts to contain externalities;

- Working with the vision of "service industries"; that is, the multitude of transformation activities directly linked to advanced services, against the backdrop of the principles of environmental sustainability.

These specific findings, just listed, are intended to rank the main ideas that emerge from the research that has been presented. We have provided biophysical indicators to complement other more conventional ones. In this regard, the following should be taken into account. First, research that affects ecological and social metabolisms are complex, because they must address multiple variables, which are often difficult to fit into a holistic discourse. Second, this research, which is only the beginning of others that should be encouraged along a similar line, while being complemented with other indicators, has the added value that it puts these variables on the table. They take precedence in a very dynamic regional economy, a leader in historical industrial growth, and with an important process of deindustrialization, as has been indicated in the work.

This study is a beginning and is simple and modest. However, the direction is clear: to structure the economy in a different way, especially in it is more specific area of measuring 
the consequences of human activity on the environment with alternative indicators. The alignment is complete with the principles governing the United Nations SDGs. Although the research is strictly empirical, it is supported by extensive economic literature. This literature is not exhaustive and the authors have not considered it necessary to make further extensions that would excessively lengthen the text.

The research should continue with the aspects stated above. The COVID-19 crisis has helped to rethink our patterns of growth, the ways we operate in the markets, and the supposedly immovable principles of macroeconomics. Modestly, we think this work is incremental in this direction. The present study can serve as a possible methodological guide for other regional economic studies. Studies on sustainability often have methodological difficulties due to their complexity in the choice and process of indicators. We believe that the simplicity of our study, at this point, with the adoption of robust variables in terms of their explanation and the mathematical method chosen, can facilitate their application to other cases.

Author Contributions: C.M., E.S. conceived the methodology; E.S., J.P.-M. performed the data processing; C.M., E.S., M.B.-F. performed the analysis and wrote the paper. All authors have read and agreed to the published version of the manuscript.

Funding: This work was supported by the research grant Mediterranean Capitalism: Successes and failures of industrial development in Spain, 1720-2020, PGC2018 093896-B-100, directed by Jordi Catalan and financed by the Spanish Ministry of Economy.

Data Availability Statement: Data available in a publicly accessible repository that does not issue DOIs. Publicly available datasets were analyzed in this study. This data can be found here: http:/ / economia.gencat.cat/ca/ambits-actuacio/economia and https://www.idescat.cat/?lang=en.

Acknowledgments: The authors appreciate the support and help of the Spanish Ministry of Economy and Caixa d'Enginyers of Catalonia.

Conflicts of Interest: The authors declare no conflict of interest.

Appendix A. Sources and Data

\begin{tabular}{cc}
\hline Data & Source \\
\hline Population & Idescat \\
GDP & Idescat \\
Index Prices & Idescat \\
Gini Index & Idescat \\
Energy consumption (ktep) & Institut Català d'Energia (ICE) \\
Water consumption & Idescat \\
$\mathrm{CO}_{2}$ emissions & Oficina Catalana Canvi Climàtic (OCCC) \\
\hline
\end{tabular}

\section{Appendix B. The Analysis of Main Components}

Principal component analysis (ACP) is a statistical technique for synthesizing information or reducing the size of the number of variables [4,45-47]. That is, given a database with many variables, the goal is to reduce them to a smaller number by losing as little information as possible. This involves transforming a set of correlated variables into a smaller set of uncorrelated variables, called principal components.

The ACP can use the correlation matrix or the covariance matrix. While, in the first option, importance is given to all variables as they may be (in the opinion of the researcher) equally relevant, in the second option, it can be used when all variables have the same unit of measurement and it is considered necessary to highlight the variables depending on their degree of variability. Because the $q$ new variables or main components are obtained as linear combinations of the original variables, the components are ordered according to the percentage of variance they explain. In this sense, the first component will be the most important because it explains the highest percentage of variance in the data. The main 
components have a variety of useful properties [48]. The general way to calculate the first major component (PC1) is

$$
\mathrm{PC} 1=\mathrm{b}_{11}\left(\mathrm{X}_{1}\right)+\mathrm{b}_{12}\left(\mathrm{X}_{2}\right)+\ldots+\mathrm{b}_{1 \mathrm{p}}\left(\mathrm{X}_{\mathrm{p}}\right),
$$

where $b \_1 p$ is the coefficient of the variable pth, which is the eigenvector of the covariance matrix between the variables, and X_p is the value of the variable pth. There are several methods for determining the optimal number of factors, such as the screen test, the variance ratio, the residue analysis, and the a priori hypotheses. The Kaiser-Guttman rule has been used most often to determine the optimal number of components. This rule states that the number of extracted factors should be equal to the number of components with an eigenvalue greater than one. The reason for choosing this value is that the variance of the factor must be at least as large as that of a single standardized original variable. The values of the main components will be different depending on how the variables are used $[49,50]$, among others.

\section{References}

1. Bericat, E.; Jimenez-Rodrigo, M.L. The Quality of European Societies A Compilation of Composite Indicators; Social Indicators Research Series; Springer: Berlin/Heidelberg, Germany, 2019.

2. Comissió Estadística de les Nacions Unides. Marco de Indicadores Mundiales para los Objetivos de Desarrollo Sostenible y Metas de la Agenda 2030 para el Desarrollo Sostenible; Comissió Estadística de les Nacions Unides: New York, NY, USA, 2017.

3. Corvo, L.; Pastore, L.; Manti, A.; Iannaci, D. Mapping Social Impact Assessment Models: A Literature Overview for a Future Research Agenda. Sustainability 2021, 13, 4750. [CrossRef]

4. Çoban, S.; Topcu, M. The nexus between financial development and energy consumption in the EU: A dynamic panel data analysis. Energy Econ. 2013, 39, 81-88. [CrossRef]

5. Deng, X.; Li, Y.; Liu, H.; Zhao, Y.; Yang, Y.; Xu, X.; Cheng, X.; Wit, B.D. Examining Energy Consumption and Carbon Emissions of Microbial Induced Carbonate Precipitation Using the Life Cycle Assessment Method. Sustainability 2021, 13, 4856. [CrossRef]

6. Global Risk Proöle. ESG Index 2019. Measure of Risks for 177 Countries 2019a. Available online: https://risk-indexes.com/wp-content/uploads/2020/01/Brochure_ESG_EN_2019.pdf (accessed on 5 February 2021).

7. Global Risk Proöle. ESG Index 2019. Technical Methodology 2019b. Available online: https://risk-indexes.com/wp-con-tent/ uploads/2020/01/Brochure_ESG_EN_2019.pdf (accessed on 5 February 2021).

8. Gösling, S.; Hansoonb, C.B.; Hörstmeierc, O.; Sagge, S. Ecological footprint analysis as a tool to assess tourism sustainability. Ecol. Econ. 2002, 43, 2-3. [CrossRef]

9. Georgescu-Roegen, N. Energy and Economic Myths. South. Econ. J. 1975, 41, 347. [CrossRef]

10. Murray, I. Geografies del Capitalisme Balear: Poder, Metabolisme Socioeconòmic i Petjada Ecològica D'una Su-Perpotència Turística. Ph.D. Thesis, Departament de Ciències de la Terra, Universitat de les Illes Balears, Palma, Spain, 2012.

11. Vallcaneras, L. Proposta D'indicadors. Cap a un Indicador Sintètic Mediambiental; Document Intern; Consell Econòmic i Social de les Illes Balears: Palma, Spain, 2020.

12. Van de Kerk, G.; Manuel, A. Sustainable Society Index 2014. The Hague: Sustainable Society Foundation. 2014. Available online: http:/ / www.ssÖndex.com/ssi2014/wp-content/uploads/pdf/SSI2014.pdf (accessed on 5 February 2021).

13. Pérez, C. Technological Revolutions, Paradigm Shifts and Socio-institutional Change. In Globalization, Economic Development and Inequality: An Alternative Perspective; Edward Elgar Publishing: Cheltenham, UK, 2014; pp. 217-242. [CrossRef]

14. Hsu, A.; Emerson, J.; Levy, M.; De Sherbinin, A.; Johnson, L.; Malik, O.; Schwartz, J.; Jaiteh, M. The 2014 Environmental performance Index; Yale Center for Environmental Law \& Policy: New Haven, CT, USA, 2014; Available online: http://www.ciesin.org/ documents/2014_epi_report.pdf (accessed on 5 February 2021).

15. Stepping, K.M.K. Challenges in Measuring the State of the Environment in Developing Countries. A Literature Review; Discussion Paper 25/2013; Deutsches Institut fur Entwicklungspolitik: Bonn, Germany, 2013.

16. Kaly, U.; Pratt, C.; Mitchell, J. The Environ- mental Vulnerability Index (EVI) 2004. Technical report 384. SOPAC (South PaciÖc Applied Geoscience Commission) 2004. Available online: http://islands.unep.ch/EVI\%202004\%20Technical\%20Report.pdf (accessed on 5 February 2021).

17. Hosseini, H.M.; Kaneko, S. Dynamic sustainability assessment of countries at the macro level: A principal component analysis. Ecol. Indic. 2011, 11, 811-823. [CrossRef]

18. Goñi, I.I.; Barberán, R. Presentación. Cuad. Económicos ICE 2021, 101. [CrossRef]

19. Krausmann, F.; Wiedenhofer, D.; Lauk, C.; Haas, W.; Tanikawa, H.; Fishman, T.; Haberl, H. Global socio-economic material stocks rise 23-fold over the 20th century and require half of annual resource use. Proc. Natl. Acad. Sci. USA 2017, 114, 1880-1885. [CrossRef]

20. Krausmann, F.; Wiedenhofer, D.; Haberl, H. Growing stocks of buildings, infrastructures and machinery as key challenge for compliance with climate targets. Glob. Environ. Chang. 2020, 61, 102034. [CrossRef] 
21. Carpintero, O. El Metabolismo Económico Regional Español; FUHEM Ecosocial: Madrid, Spain, 2015; 1127p.

22. O'Neill, D.W.; Fanning, A.L.; Lamb, W.F.; Steinberger, J.K. A good life for all within planetary bounda-ries. Nat. Sustain. 2018, 1, 88-95. [CrossRef]

23. Kitzes, J. An Introduction to Environmentally-Extended Input-Output Analysis. Resources 2013, 2, 489-503. [CrossRef]

24. Leontief, W. Input-output analysis. The new palgrave. Dict. Econ. 1987, 2, 860-864.

25. Sraffa, P. Production of Commodities by Means of Commodities: Prelude to a Critique of Economic Theory; CUP Archive: Cambridge, UK, 1975.

26. Witt, U. (Ed.) Evolutionary Economics. In Aldershot; Edward Elgar Publishing: Cheltenham, UK, 1993.

27. Witt, U. What is specific about evolutionary economics? In Rethinking Economic Evolution; Edward Elgar Publishing: Cheltenham, UK, 2016.

28. Nelson, R.R.; Dosi, G.; Helfat, C.E.; Winter, S.G. Modern Evolutionary Economics: An Overview; Cambridge University Press: Cambridge, UK, 2018.

29. Rifkin, J. The Zero Marginal Cost Society: The Internet of Things, the Collaborative Commons, and the Eclipse of Capitalism; St. Martin's Press: New York, NY, USA, 2014.

30. Schwab, K.; Sala-i-Martín, X. The Global Competitiveness Report 2013-2014: Full Data Edition; World Economic Forum: Geneva, Switzerland, 2016.

31. Vera, F.; Ivars, J.A. Measuring sustainability in a mass tourist destination: Pressures, perceptions and policy responses in Torrevieja, Spain. J. Sustain. Tour. 2003, 11, 181-203.

32. Williams, A.; Shaw, G. Tourism and the environment: Sustainability and economic restructuring. In Sustainable Tourism: A Geographical Perspective; Addison Wesley Longman Ltd: Harlow, UK, 1998; pp. 49-59.

33. Farrell, B.H.; Twining-Ward, L. Reconceptualizing Tourism. Ann. Tour. Res. 2004, 31, 274-295. [CrossRef]

34. Schipper, L.; Howarth, R.; Carlassare, E. Energy intensity, sectoral activity, and structural change in the Nor-wegian economy. Energy 1992, 17, 215-233. [CrossRef]

35. Sue Wing, I.; Eckaus, R.S. Explaining Long-Run Changes in the Energy Intensity of the Us Economy; MIT Joint Program on the Science and Policy of Global Change: Cambridge, MA, USA, Report No.116.

36. Esseghir, A.; Khouni, L.H. Economic growth, energy consumption and sustainable development: The case of the Union for the Mediterranean countries. Energy 2014, 71, 218-225. [CrossRef]

37. Mazzucato, M. A mission-oriented approach to building the entrepreneurial state. Innovate UK 2014.

38. Joint Research Centre-European Commission. Handbook on Constructing Composite Indicators: Methodology and User Guide; OECD Publishing: Paris, France, 2008.

39. Rüstow, A.; Maier-Rigaud, F.P.; Küpper, H. Das versagen des Wirtschaftsliberalismus. 1950. Available online: http:/ / ruestow.org/ (accessed on 5 February 2021).

40. Saisana, M.; Saltelli, A. Appendix II. Preliminary sensitivity analysis. In 2012 Environmental Performance Index and pilot trend Environmental Performance Index; Emerson, J.W., Hsu, A., Levy, M.A., de Sherbinin, A., Mara, V., Esty, D.C., Jaiteh, M., Eds.; Yale Center for Environmental Law and Policy: New Haven, CT, USA, 2012; pp. 93-99. Available online: http:/ /www.ciesin.org/ documents / 2012-epi-full-report.pdf (accessed on 5 February 2021).

41. Saisana, M.; Weziak-Bialowolska, D.M. JRC Statistical audit on the Environment and Gender Index; International Union for Conservation of Nature (IUCN), Ed.; The Environment and Gender Index (EGI): Washington, DC, USA, 2013; pp. 143-153. Available online: http:/ /genderandenvironment.org/wp-content/uploads/2014/12/The-Environ-ment-and-Gender-Index-2013-Pilot.pdf (accessed on 5 February 2021).

42. Schenker, N.; Taylor, J.M.G. Partially parametric techniques for multiple imputation. Comput. Stat. Data Anal. 1996, 22, 425-446. [CrossRef]

43. Prescott-Allen, R. The Wellbeing of Nations. A Country-by-Country Index of Quality of Life and the Environment; Island Press: Washington, DC, USA, 2001.

44. Pradhan, R.P.; Arvin, M.B.; Hall, J.H.; Bahmani, S. Causal nexus between economic growth, banking sector development, stock market development, and other macroeconomic variables: The case of ASEAN countries. Rev. Financ. Econ. 2014, 23, 155-173. [CrossRef]

45. Lewis-Beck, M. Factor Analysis and Related Techniques. Sage: Thousand Oaks, CA, USA, 1994.

46. Herwartz, H.; Walle, Y.M. Determinants of the link between financial and economic development: Evidence from a functional coefficient model. Econ. Model. 2014, 37, 417-427. [CrossRef]

47. Radovanović, M.; Filipović, S.; Golušin, V. Geo-economic approach to energy security measurement-Principal component analysis. Renew. Sustain. Energy Rev. 2018, 82, 1691-1700. [CrossRef]

48. Moradzadeh, A.; Sadeghian, O.; Pourhossein, K.; Mohammadi-Ivatloo, B.; Anvari-Moghaddam, A. Improving Residential Load Disaggregation for Sustainable Development of Energy via Principal Component Analysis. Sustainability 2020, $12,3158$. [CrossRef]

49. Rao, C.R. The use and interpretation of principal component analysis in applied research. Sankhya Indian J. Stat. Ser. A 1964, 26, 329-358.

50. Murthy, K.V.B.; Kalsie, A. Measurement of International Currency Crises: A Panel Data Approach using Composite Indices. Vikalpa 2013, 38, 13-36. [CrossRef] 